\title{
Romiplostim as a treatment for immune thrombocytopenia: a review
}

\author{
This article was published in the following Dove Press journal: \\ Journal of Blood Medicine \\ 19 January 2015 \\ Number of times this article has been viewed
}

\author{
Sarah Chalmers ${ }^{1,2}$ \\ Michael D Tarantino ${ }^{1-3}$ \\ 'University of Illinois College of \\ Medicine - Peoria, ${ }^{2}$ The Children's \\ Hospital of Illinois, ${ }^{3}$ The Bleeding and \\ Clotting Disorders Institute, Peoria, \\ Illinois, USA
}

\begin{abstract}
Immune thrombocytopenia" (ITP) is an autoimmune disorder that leads to peripheral destruction, as well as a decreased production of platelets. ITP most commonly presents as mild mucocutaneous bleeding. Though it is rare, the leading cause of mortality in persons with ITP is intracranial hemorrhage and those that do not respond to therapy are at increased risk. Our understanding of the pathophysiology of ITP has evolved immensely, especially over the last 60 years. The discovery of the platelet-production stimulator, thrombopoietin (TPO), lent clarity to an earlier hypothesis that inhibition of platelet production at the level of the megakaryocyte, at least in part, accounts for thrombocytopenia in adults with ITP. This facilitated the development of TPO-based therapies to treat ITP. Thrombopoietin receptor agonists are one of the most recent treatments to enter the landscape. Original production of a recombinant human TPO was halted after clinical trials revealed the untoward effect of autoantibodies to the recombinant human TPO with cross-reactivity to endogenous TPO. Next-step development focused on stimulation of the TPO receptor with fewer immunogenic agents. Currently, two such thrombopoietin receptor agonists, romiplostim and eltrombopag, are licensed in the USA to treat thrombocytopenia in adults with persistent or chronic ITP. Ongoing research will assess their efficacy in other immune-mediated and nonimmune-mediated primary and secondary thrombocytopenias.
\end{abstract}

Keywords: thrombopoietin, thrombopoietin receptor agonist, megakaryocyte, peptibody

\section{Introduction}

"Immune thrombocytopenia" (ITP) is an autoimmune disease characterized by isolated thrombocytopenia (platelet count $<100,000 \mathrm{mg} / \mathrm{dL}$ ) with normal morphology of red and white blood cells, normal-to-large platelets on peripheral blood smear, normal-appearing bone marrow, and absence of other causes. It remains a diagnosis of exclusion. It is often identified incidentally on routine laboratory testing but may also present clinically with mucocutaneous bleeding such as petechiae or ecchymoses. The estimated incidence of ITP is 1.9 to 6.4 per 100,000 per year in children and 3.3 per 100,000 per year in adults. ${ }^{1}$ ITP occurs in both adults and children, though the course of the disease is quite different between the two groups. Children most commonly present with abrupt onset of mucocutaneous manifestations, often with an antecedent viral illness. Resolution most commonly occurs spontaneously within 6 months of onset. Though relapses of severe thrombocytopenia occur in $25 \%$ of children after initial treatment, only $5 \%$ have severe thrombocytopenia requiring treatment beyond 1 year from the time of diagnosis. ${ }^{2}$ The incidence in girls and boys is roughly equal. Adults, in contrast, tend to have a more insidious onset and a chronic disease course, with women affected more than men at a rate of approximately $1.3: 1.0$ to $3.0: 1.0 .^{3,4}$ In adults,
Correspondence: Michael D Tarantino 68II North Knoxville Avenue,

Suite A, Peoria, IL 61614

Tel +l 3096925337

Fax +I 3096933913

Email mtarantino@ilbcdi.org 
persistence of thrombocytopenia and relapse or recurrence of thrombocytopenia are common. Our understanding of ITP as a disease process and how to treat it has evolved significantly over the past century. This review illustrates this progression, with a focus on the relatively new treatment of ITP with the thrombopoietin receptor agonist (TRA) romiplostim.

\section{Pathophysiology}

The established pathophysiology of ITP has progressed from identification of the disease as a platelet-destruction process in the peripheral blood, to an autoimmune process as the cause of the destruction, and, further, to an autoimmune destruction of platelets and inhibition of platelet production. Historically, ITP was first distinguished from the purpura caused by sepsis by Paul Gottfried Werlhof in the eighteenth century who coined the term "morbus maculosus of Werlof". 5 Nearly 200 years later a landmark discovery by William J Harrington and James W Hollingsworth demonstrated that transient thrombocytopenia occurred in healthy recipients with transfusion of plasma from ITP-affected patients. ${ }^{6}$ In 1965, Shulman et al proposed that antibodies were responsible for the platelet destruction. Their study showed that the "platelet-depressing factor in ITP sera" was adsorbed by platelets and was present in the immunoglobulin $\mathrm{G}$ fraction of the plasma. ${ }^{7}$ The first platelet antigen identified in ITP was on glycoprotein IIb/IIIIa. It is now known that multiple antibody idiotypes may be present in any given case of ITP. ${ }^{8-10}$ In the late $1980 \mathrm{~s}$, it became apparent that platelet production may also be affected. ${ }^{11,12}$ Studies showed that while there were a normal or increased number of megakaryocytes and increased cell cycling of the platelet progenitor, the platelet turnover was inappropriately normal or decreased. This suggested that the predominant effect of antibodies on platelet production was toward the completion of the thrombopoietic process. In addition, previous studies had demonstrated binding of antibodies to the megakaryocyte membrane. ${ }^{11-13}$ Given this newfound evidence, the search was on for a therapeutic agent that could overcome the deleterious effects of autoantibodies on the megakaryocyte.

\section{Treatment}

The standard of treatment for ITP has progressed from phlebotomy in the mid-1800s; to transfusion; splenectomy beginning in the early 1900s; and, most recently, medical management. ${ }^{14}$ The recent "International consensus report" guidelines and American Society of Hematology guidelines recommend observation as the first line of treatment in children without bleeding, regardless of platelet count. ${ }^{15,16}$
Treatment is recommended for patients with persistent or recurrent bleeding that interferes with quality of life. In adults, initiation of treatment is recommended for a platelet count $<30 \times 10^{9} / \mathrm{L}$. First-line medical management consists of corticosteroids, intravenous immunoglobulin (IVIg), or anti-D immunoglobulin (anti-D). ${ }^{15,16}$ IVIg alone in children and with corticosteroids in adults, has been shown to afford the most rapid rise in the platelet count. ${ }^{17-19}$ Recommended treatment for those who do not respond to initial therapeutic agents or who relapse after treatment differs between children and adults. In children who relapse following initial successful treatment, repeated use of first-line therapies is recommended for as long as they respond, though long-term use of corticosteroids should be avoided. Rituximab, high-dose methylprednisolone, or high-dose dexamethasone, is recommended for those who have persistent bleeding despite treatment with first-line therapies. Rituximab is often considered first to avoid the adverse effects of longer-term corticosteroids, although the platelet response rate and durability of response to rituximab is highly variable. ${ }^{20-24}$ Splenectomy has been shown to be highly effective in children, with a $70 \%-80 \%$ sustained response rate. However, the mortality rate secondary to sepsis in splenectomized children (up to 3\%) is greater than the mortality rate in children secondary to ITP $(<0.5 \%)$ and therefore it is recommended that splenectomy be delayed for at least 12 months after diagnosis. ${ }^{15-19}$ Salvage therapies, including alemtuzumab, azathioprine, danazol, dapsone, colchicine, combination chemotherapy, cyclophosphamide, cyclosporine, interferon-alpha, 6-mercaptopurine, and vinca alkaloids have been suggested for those who do not respond to the already listed treatments and continue to have severe disease or decreased quality of life, though evidence for efficacy is limited and adverse effects are often severe. ${ }^{25-34}$

For adults with ITP that is unresponsive to initial treatment, and for those that experience relapse after initial drug treatment success, splenectomy or TRAs are recommended. ${ }^{15,16}$ TRAs are a relatively new treatment option for the management of persistent or refractory ITP and may provide a means to defer or avoid splenectomy.

\section{Thrombopoietin}

Much of the 1900s witnessed major advances in our understanding of platelet production and regulation. Key findings included the discovery that platelet counts are stable in the nonpathologic patient; a "normal" platelet count is highly variable from one person to another; platelet size is inversely related to the platelet number; platelet mass and not platelet count determines the need for change in platelet production; and, 
finally, there is an inverse relationship between the platelet count and megakaryocyte ploidy and size. ${ }^{35}$ Though the mechanism of platelet production was becoming clear, the consummate platelet growth factor was difficult to isolate. In the early 1990s, a putative molecule was isolated that stimulated megakaryocyte production, size, ploidy, and increased the platelet count. It was eventually verified as the main platelet-production stimulator and named "thrombopoietin" (TPO). ${ }^{36-39}$ TPO is presumed to be produced constitutively by the liver and is cleared by specific binding to TPO receptors on platelets. Thus, TPO level (distinct from TPO production) is inversely proportional to platelet production as well as platelet mass. ${ }^{39}$

\section{Thrombopoietin receptor agonists}

Following these discoveries, two TRAs were developed, recombinant human thrombopoietin (rhTPO) and polyethylene glycol (PEG)-ylated-recombinant human megakaryocyte growth and development factor (PEG-rhMGDF). Both were shown to be effective at treating several disease processes including raising the platelet count in chemotherapy-induced thrombocytopenia, myelodysplastic syndrome, and ITP. ${ }^{40}$ They were also effective at increasing platelet yields in healthy and autologous platelet donors. ${ }^{41-47}$ However, a small portion of healthy volunteers developed neutralizing antibodies to PEG-rhMGDF that then acted on endogenous TPO resulting in sometimes protracted thrombocytopenia. All volunteers eventually recovered without further complication. ${ }^{47}$ Understandably, the development of PEG-rhMGDF and rhTPO for clinical purposes was discontinued.

Simultaneously with the recombinant TPO trials, were ongoing efforts to discover other, less immunogenic, TRAs. A peptide pair inserted into the arm of an immunoglobulin $G$ heavy-chain molecule was tested in mice. Results showed that this peptibody, later named romiplostim (alternatively, AMG 531, AMP-2, or Nplate ${ }^{\circledR}$ ) was capable of binding to the extracellular domain of the TPO receptor and stimulating megakaryocyte growth and platelet production. ${ }^{48-50}$ Trialing romiplostim for the treatment of ITP was an obvious choice, as the autoantibodies in ITP not only destroy circulating platelets but also inhibit platelet production at the level of the megakaryocyte.

\section{Clinical experience with romiplostim}

Romiplostim (Nplate) was approved by the US Food and Drug Administration (FDA) on August 22, 2008. At the time of approval, the FDA considered the clinical experience with romiplostim to be limited, and safety concerns led to the institution of a risk evaluation and mitigation strategy (REMS) that included restricted distribution and mandatory safety data collection. The safety concerns included bone-marrow changes, higher risk for blood clots, possible worsening of blood cancers, and worsening low blood platelet count after stopping the drugs. However, the underlying medical conditions in patients with chronic ITP made the safety data collected by the REMS program difficult to interpret. On December 6, 2011, the FDA approved modifications to the REMS for romiplostim, lifting the restricted distribution and the requirement of additional safety data collection. Prescribers, health care institutions, pharmacies, and patients no longer have to enroll in the REMS programs in order to prescribe, dispense, or take romiplostim. A similar REMS was instituted and later lifted for eltrombopag. ${ }^{51}$

Currently, both the American Society of Hematology ITP management guidelines and the "International consensus report" guidelines recommend the use of TRAs for adults with ITP that persists following splenectomy or in patients who are not candidates for splenectomy and for who at least one other treatment has failed. ${ }^{15,16}$ Current evidence on the use of romiplostim in adults with ITP suggests that it increases the platelet count, decreases bleeding; decreases the need for rescue treatments; decreases the amount of corticosteroids required; increases quality of life; and, in isolated cases, is associated with ITP remission. ${ }^{51-58}$ A Cochrane Review from 2011 included six randomized control trials with a total of 808 adult patients with chronic ITP and compared TRAs with placebo or standard of care. ${ }^{59}$ They confirmed that TRAs have a greater platelet response than placebo or standard of care; they also concluded that further evidence is needed to evaluate their effect on overall survival and the risk of bleeding in patients with chronic ITP. ${ }^{59}$ In a Phase I-II trial of 26 patients with and without splenectomy who received 24 weeks of treatment with romiplostim, $80 \%$ of patients had an overall response rate with a minimum platelet count of 50,000 per cubic millimeter, which is similar to the response seen with corticosteroids and IVIg and greater than the response seen with anti-D, splenectomy, and other second-line therapies. Overall a response rate of approximately $80 \%$ has been seen in most subsequent studies as well. ${ }^{51,53}$ Kuter et al reported the results of a Phase III trial of 234 adult patients with ITP who had not undergone splenectomy, compared romiplostim treatment with standard of care - glucocorticoids being the most common standard-of-care treatment noted. They found that the rate of response was 2.3-times higher, incidence of treatment failure was lower (romiplostim, 11\%; standard of care, $30 \% ; P<0.001)$, and splenectomy was utilized less frequently 
(romiplostim, 9\%; standard of care, 36\%; $P<0.001$ ) in those patients who were treated with romiplostim. ${ }^{53}$ In another Phase III trial in 63 splenectomized and 62 non-splenectomized adult patients with ITP comparing 24 weeks of treatment with romiplostim or placebo, $87 \%$ of patients treated with romiplostim vs $38 \%$ in the placebo group were able to reduce or discontinue concurrent therapy, including corticosteroids, and more patients in the placebo group than in the romiplostim group required rescue therapy $(P<0.001) .{ }^{51}$ In another report from the romiplostim clinical-development program, patients who had been randomized to receive either romiplostim or placebo were evaluated for bleeding risk. Results demonstrated that a significantly large proportion of the patients in the placebo arm had adverse bleeding events of moderate or greater severity than those treated with romiplostim (34\% vs $15 \%, P=0.018) .{ }^{60}$ Recent studies have demonstrated sustained platelet count and/or remission following the discontinuation of TRAs in some adults with chronic ITP. ${ }^{58,61,62}$ Interestingly, Ghadaki et al noted that the dose of romiplostim needed to reach a platelet count greater than $100 \times 10^{9} / \mathrm{L}$ was much smaller than the dosing that has been studied in clinical trials. ${ }^{58}$ In another study, the TRA was discontinued due to stability of platelet count with tapering of the dose. ${ }^{62}$ In addition, one study also assessed the presence of autoantibodies and found that the antibody titer decreased as the platelet count increased. ${ }^{58}$ The author hypothesized that this may be due to induced immune tolerance to the platelet auto-antigen. Whether TRA use induced immune tolerance, or merely coincided with spontaneous resolution leading to normalization of the platelet count in these patients, requires further investigation.

Romiplostim is a well-tolerated treatment. Most reported adverse effects have been mild-moderate and have not led to cessation of treatment. ${ }^{53}$ Some of the more common reported adverse effects are mild-moderate post-injection headache, fatigue, and arthralgias. ${ }^{51,52}$ Serious adverse events that continue to be under investigation include increased bone-marrow reticulin, rebound severe thrombocytopenia, thrombocytosis, and increased immunoblast proliferation. Increased risk of thrombosis has also been questioned, however current studies have attributed thrombosis to other disease processes such as fracture. ${ }^{63}$ Bone-marrow fibrosis has been reported in multiple clinical trials with the use of TRAs, although it has also been shown that the fibrosis is reversible with discontinuation of the drug. ${ }^{64-67} \mathrm{Up}$ to $70 \%$ of the general population has been shown to have some level of reticulin bone-marrow fibrosis, as high as MF-1 on the European Consensus Method and previous studies have shown that ITP patients who have been treated with a TRA do not show increased fibrosis as compared with the healthy population. ${ }^{68-70}$ The fibrosis demonstrated with TRA use has not been clinically significant to date. ${ }^{65-67}$ In the largest scale study of bone-marrow fibrosis in adult ITP patients who have been treated with TRAs, 50\% (4/8) of patients showed significant increase following a median treatment duration of 2.7 years. However, no patient had an MF level greater than MF-1. ${ }^{65}$ Preliminary data from a retrospective study of 33 children with chronic ITP treated with a TRA has shown similar results. Twenty-four bone-marrow biopsies were completed, ten of which were performed after more than 2 years of treatment with a TRA. None of the biopsies showed fibrosis greater than MF-1. The percentage of patients with a significant increase in fibrosis has not yet been reported. ${ }^{63}$

Rebound worsening thrombocytopenia following discontinuation of treatment has been documented. In one study, rebound worsening thrombocytopenia occurred after cessation of treatment with romiplostim and persisted for 3-17 days. ${ }^{52}$ However, the platelet count returned to normal without sequelae. No adverse events occurred that could be attributed to this drop. Two of the four patients were treated with rescue treatment. Regarding thrombocytosis, given the mechanism of the drug, thrombocytosis is certainly a plausible risk. Current manufacturer instructions recommend discontinuing the drug if platelet count exceeds $400 \times 10^{9} / \mathrm{L}$. The discontinuation of the drug is debated by expert opinion, as the evidence does not support that the elevated platelet count increases patient risk for thrombosis, and, due to the aforementioned potential for a precipitous drop in platelet count following abrupt cessation of the drug, risk of discontinuation may outweigh the benefit. ${ }^{71}$

Immunoblast proliferation in patients with myelodysplastic syndrome is a potential untoward effect of hematologic growth factors. Giagounidis et al reported the results of a comparison of romiplostim and placebo for treatment of thrombocytopenia in patients with myelodysplastic syndrome. ${ }^{72}$ Despite promising results showing increased platelet counts, decreased number of bleeding events, and decreased platelet transfusions in the romiplostim arm, the study was discontinued early due to concerns of excess blasts and the rate of AML. The AML rates were $6.0 \%$ in the romiplostim group and $4.9 \%$ in the placebo group (hazard ratio, 1.20; 95\% confidence interval, 0.38-3.84). The overall survival rates were similar.

Clinical trials assessing the safety and efficacy of use of romiplostim for chronic ITP in pediatric patients are recent or ongoing. ${ }^{73-77}$ Bussel et al reported the results of a 
Phase I/II, multicenter prospective, randomized, double-blind, placebo-controlled study evaluating the safety and efficacy of treatment with romiplostim in children with chronic ITP. ${ }^{73}$ The overall response rate was similar to those seen in adults and the adverse effects profile was favorable, with no treatment-related serious adverse events. No bone-marrow biopsies were obtained. Children received romiplostim $(n=17)$ or placebo $(n=5)$ weekly for 12 weeks, with dose modification to maintain platelet counts in the hemostatic range. Eighty-eight percent of children on the romiplostim arm of the study achieved a platelet count in the target range for at least 2 weeks. Also, the treatment group was able to maintain the raised platelet count significantly longer than the placebo group (0-11 weeks in the treatment group with a mean of 7 weeks and 0 weeks in the placebo group).${ }^{73}$ Patients from this Phase I/II trial and an ongoing randomized Phase III trial of romiplostim vs placebo in children with chronic ITP were/are given the opportunity to participate in an openlabel extension trial of romiplostim. Tarantino et al reported on the preliminary results of this extension trial, in 22 mostly non-splenectomized pediatric patients, which revealed that long-term (up to 172 weeks') treatment with romiplostim maintained platelet counts in pediatric patients with chronic ITP without significant toxicity. ${ }^{75}$ The median romiplostim dose in this study was $6.0 \mu \mathrm{g} / \mathrm{kg}$ at week 1 and $3.5 \mu \mathrm{g} / \mathrm{kg}$ at week 168 . Four patients discontinued romiplostim. None of the reported four serious adverse events was deemed treatment related. In another randomized study in 18 children with chronic ITP, Elalfy et al reported a favorable platelet response rate of $83 \%(10 / 12)$ children on the romiplostim arm, with a platelet response that was sustained for at least 3 weeks following treatment. ${ }^{74}$ In a small retrospective study of romiplostim treatment of children with chronic ITP, Pasquet et al reported a platelet response rate of $50 \%$ with good tolerability. ${ }^{76}$

Other studies are also currently underway investigating the safety and efficacy of romiplostim for the treatment and prevention of thrombocytopenia secondary to chemotherapy in malignancies such as non-Hodgkin lymphoma, multiple myeloma, and non-small-cell lung cancer. ${ }^{76-80}$ Also, data are being collected in the NPlate Pregnancy Exposure Registry to assess the prevalence of birth defects in pregnant women treated with romiplostim. ${ }^{81}$

Eltrombopag is currently FDA approved for the treatment of thrombocytopenia secondary to aplastic anemia and has been shown to be beneficial in the treatment of thrombocytopenia secondary to hepatitis $\mathrm{C}$ infection. Studies are also underway on the use of romiplostim in patients with aplastic anemia and secondary thrombocytopenia related to chronic hepatitis $\mathrm{C}$ infection. ${ }^{82,83}$

\section{Conclusion}

ITP is a relatively common disorder that affects both children and adults. Over the past century several landmark discoveries, including further understanding of the pathophysiology of ITP and the discovery of TPO, have led to the development of novel treatments. Romiplostim has been shown to be safe and effective at raising and sustaining the platelet count in patients with chronic ITP. Though romiplostim is generally well-tolerated, some potentially concerning side effects such as bone-marrow reticulin accumulation and thrombosis have been documented, justifying ongoing surveillance. Further investigation into the use of romiplostim in other disease processes such as ITP in children, thrombocytopenia secondary to hepatitis $\mathrm{C}$, aplastic anemia, and chemotherapy-induced thrombocytopenia may broaden the utility of this important drug. ${ }^{84,85}$

\section{Disclosure}

Dr Chalmers declares no conflicts of interest in this work; Dr Tarantino is an advisor (with consulting fees paid) for Amgen, Baxter, Biogen, Grifols, Kedrion, Novo Nordisk, and Pfizer; provides research support to Baxter, Grifols, Novo Nordisk; is in speaker programs for Biogen, Grifols, and Pfizer; and is a clinical trials investigator with Amgen, Baxter, Biogen, and Rigel.

\section{References}

1. Terrell DR, Beebe LA, Vesely SK, Neas BR, Segal JB, George JN. The incidence of immune thrombocytopenic purpura in children and adults: A critical review of published reports. Am J Hematol. 2010;85(3): 174-180.

2. Imbach P, Akatsuka J, Blanchette VS, et al. Immunthrombocytopenic purpura as a model for pathogenesis and treatment of autoimmunity. Eur J Pediatr. 1995;154(9 Suppl 4):S60-S64.

3. Frederiksen $\mathrm{H}, \mathrm{Schmidt} \mathrm{K}$. The incidence of idiopathic thrombocytopenic purpura in adults increases with age. Blood. 1999;94(3):909-913.

4. Neylon AJ, Saunders PW, Howard MR, Proctor SJ, Taylor PR; Northern Region Haematology Group. Clinically significant newly presenting autoimmune thrombocytopenic purpura in adults: a prospective study of a population-based cohort of 245 patients. Br J Haematol. 2003;122(6): 966-974.

5. Burt S. Purpura hemorrhagiva, or morhus maculosus of Werlhof. NEngl J Med. 1900;143:441-444.

6. Harrington WJ, Minnich V, Hollingsworth JW, Moore CV. Demonstration of a thrombocytopenic factor in the blood of patients with thrombocytopenic purpura. J Lab Clin Med. 1951;38(1): $1-10$.

7. Shulman NR, Marder VJ, Weinrach RS. Similarities between known antiplatelet antibodies and the factor responsible for thrombocytopenia in idiopathic purpura. Physiologic, serologic and isotopic studies. Ann N Y Acad Sci. 1965;124(2):499-542. 
8. Stockelberg D, Hou M, Jacobsson S, Kutti J, Wadenvik H. Evidence for a light chain restriction of glycoprotein $\mathrm{Ib} / \mathrm{IX}$ and IIb/IIIa reactive antibodies in chronic idiopathic thrombocytopenic purpura (ITP). Br J Haematol. 1995;90(1):175-179.

9. He R, Reid DM, Jones CE, Shulman NR. Extracellular epitopes of platelet glycoprotein Ib alpha reactive with serum antibodies from patients with chronic idiopathic thrombocytopenic purpura. Blood. 1995;86(10):3789-3796.

10. van Leeuwen EF, van der Ven JT, Engelfriet CP, von dem Borne AE. Specificity of autoantibodies in autoimmune thrombocytopenia. Blood. 1982;59(1):23-26.

11. Ballem PJ, Segal GM, Stratton JR, Gernsheimer T, Adamson JW, Slichter SJ. Mechanisms of thrombocytopenia in chronic autoimmune thrombocytopenic purpura. Evidence of both impaired platelet production and increased platelet clearance. J Clin Invest. 1981;80(1): $33-40$.

12. McMillan R, Luiken GA, Levy R, Yelenosky R, Longmire RL. Antibody against megakaryocytes in idiopathic thrombocytopenic purpura. J Am Med Assoc. 239(23):2460-2462.

13. He R, Reid DM, Jones CE, Shulman NR. Spectrum of Ig classes, specificities, and titers of serum antiglycoproteins in chronic idiopathic thrombocytopenic purpura. Blood. 1994;83(4): 1024-1032.

14. Tarantino MD, Goldsmith G. Treatment of acute immune thrombocytopenic purpura. Semin Hematol. 1998;35(1 Suppl 1):28-35.

15. Provan D, Stasi R, Newland AC, et al. International consensus report on the investigation and management of primary immune thrombocytopenia. Blood. 2010;115(2):168-186.

16. Neunert C, Lim W, Crowther M, Cohen A, Solberg L Jr, Crowther MA; American Society of Hematology. The American Society of Hematology 2011 evidence-based practice guideline for immune thrombocytopenia. Blood. 2011;117(16):4190-4207.

17. Godeau B, Chevret S, Varet B, et al; French ATIP Study Group. Intravenous immunoglobulin or high-dose methylprednisolone, with or without oral prednisone, for adults with untreated severe autoimmune thrombocytopenic purpura: a randomised, multicentre trial. Lancet. 2002;359(9300):23-29.

18. Blanchette VS, Luke B, Andrew M, et al. A prospective, randomized trial of high-dose intravenous immune globulin G therapy, oral prednisone therapy, and no therapy in childhood acute immune thrombocytopenic purpura. J Pediatr. 1993;123(6):989-995.

19. Beck CE, Nathan PC, Parkin PC, Blanchette VS, Macarthur C. Corticosteroids versus intravenous immune globulin for the treatment of acute immune thrombocytopenic purpura in children: a systematic review and meta-analysis of randomized controlled trials. $J$ Pediatr. 2005;147(4):521-527.

20. Patel VL, Mahévas M, Lee SY, et al. Outcomes 5 years after response to rituximab therapy in children and adults with immune thrombocytopenia. Blood. 2012;119(25):5989-5995.

21. Bennett CM, Rogers ZR, Kinnamon DD, et al. Prospective phase $1 / 2$ study of rituximab in childhood and adolescent chronic immune thrombocytopenic purpura. Blood. 2006;107(7):2639-2642.

22. Mueller BU, Bennett CM, Feldman HA, et al; Pediatric Rituximab/ITP Study Group; Glaser Pediatric Research Network. One year follow-up of children and adolescents with chronic immune thrombocytopenic purpura (ITP) treated with rituximab. Pediatr Blood Cancer. 2009;52(2): 259-262.

23. Wang J, Wiley JM, Luddy R, Greenberg J, Feuerstein MA, Bussel JB. Chronic immune thrombocytopenic purpura in children: assessment of rituximab treatment. J Pediatr. 2005;146(2):217-221.

24. Parodi E, Rivetti E, Amendola G, et al. Long-term follow-up analysis after rituximab therapy in children with refractory symptomatic ITP: identification of factors predictive of a sustained response. $\mathrm{Br} J$ Haematol. 2009;144(4):552-558.

25. Reiner A, Gersheimer T, Slichter SJ. Pulse cyclophosphamide therapy for refractory autoimmune thrombocytopenic purpura. Blood. 1995;85(2):351-358.
26. Schiavotto C, Castamann G, Rodeghiero F. Treatment of idiopathic thrombocytopenic purpura (ITP) in patients with refractoriness to or with contraindication for corticosteroids and/or splenectomy with immunosuppressive therapy and danazol. Haematologica. 1993; 78(6 Suppl 2):29-34.

27. Facon T, Caulier MT, Wattel E, Jouet JP, Bauters F, Fenaux P. A randomized trial comparing vinblastine in slow infusion and by bolus iv injection in idiopathic thrombocytopenic purpura: a report on 42 patients. Br J Haematol. 1994;86(3):678-680.

28. Pizzuto J, Ambriz R. Therapeutic experience on 934 adults with idiopathic thrombocytopenic purpura: Multicentric Trial of the Cooperative Latin American group on Hemostasis and Thrombosis. Blood. 1984;64(6):1179-1183.

29. Figueroa M, Gehlsen J, Hammond D, et al. Combination chemotherapy in refractory immune thrombocytopenic purpura. $N$ Engl $J$ Med. 1993;328(17):1226-1229.

30. Weinblatt ME, Kochen J, Ortega J. Danazol for children with immune thrombocytopenic purpura. Am J Dis Child. 1988;142(12):1317-1319.

31. Marwaha RK, Singh RP, Garewal G, Marwaha N, Prakash D, Sarode R. Colchicine therapy in immune thrombocytopenic purpura. Acta Paediatr Scand. 1990;79(11):1118-1120.

32. Strother SV, Zuckerman KS, LoBuglio AF. Colchicine therapy for refractory idiopathic thrombocytopenic purpura. Arch Intern Med. 1984;144(11):2198-2200

33. Ishii $\mathrm{H}, \mathrm{Oh} \mathrm{H}$, Uchida Y, et al. Effect of interferon (IFN) on refractory idiopathic thrombocytopenic purpura: administration of 6 million units of recombinant IFN alpha-2b. Intern Med. 1992;31(12):1343-1347.

34. Brox AG, Howson-Jan K, Fauser AA. Treatment of idiopathic thrombocytopenic purpura with ascorbate. Br J Haematol. 1988;70(3):341-344.

35. Kuter D. Milestones in understanding platelet production: a historical overview. Br J Haematol. 2014;165(2):248-258.

36. Wendling F, Maraskovsky E, Debili N, et al. cMpl ligand is a humoral regulator of megakaryocytopoiesis. Nature. 1994;369(6481):571-574.

37. Kaushansky K, Lok S, Holly RD, et al. Promotion of megakaryocyte progenitor expansion and differentiation by the c-Mpl ligand thrombopoietin. Nature. 1994;369(6481):568-571.

38. de Sauvage FJ, Hass PE, Spencer SD, et al. Stimulation of megakaryocytopoiesis and thrombopoiesis by the c-Mpl ligand. Nature. 1994;369(6481):533-538.

39. Kuter DJ, Beeler DL, Rosenberg RD. The purification of megapoietin: a physiological regulator of megakaryocyte growth and platelet production. Proc Natl Acad Sci U S A. 1994;91(23):11104-11108.

40. Basser RL, Rasko JE, Clarke K, et al. Thrombopoietic effects of pegylated recombinant human megakaryocyte growth and development factor (PEG-rHuMGDF) in patients with advanced cancer. Lancet. 1996;348(9037):1279-1281.

41. Vadhan-Raj S, Verschraegen CF, Bueso-Ramos C, et al. Recombinant human thrombopoietin attenuates carboplatin-induced severe thrombocytopenia and the need for platelet transfusions in patients with gynecologic cancer. Ann Intern Med. 2000;132(5):364-368.

42. Komatsu N, Okamoto T, Yoshida T. Pegylated recombinant human megakaryocyte growth and development factor increased platelet count in patients with aplastic anemia and myelodysplastic syndrome. Blood. 2000;96:296a

43. Rice L, Nichol JL, McMillan R, Roskos LK, Bacile M. Cyclic immune thrombocytopenia responsive to thrombopoietic growth factor therapy. Am J Hematol. 2001;68(3):210-214.

44. Goodnough LT, Kuter DJ, McCullough J, et al. Prophylactic platelet transfusions from healthy apheresis platelet donors undergoing treatment with thrombopoietin. Blood. 2001;98(5):1346-1351.

45. Kuter DJ, Goodnough LT, Romo J, et al. Thrombopoietin therapy increases platelet yields in healthy platelet donors. Blood. 2001;98(5):1339-1345.

46. Vadhan-Raj S, Kavanagh JJ, Freedman RS, et al. Safety and efficacy of transfusions of autologous cryopreserved platelets derived from recombinant human thrombopoietin to support chemotherapyassociated severe thrombocytopenia: a randomised cross-over study. Lancet. 2002;359(9324):2145-2152. 
47. Li J, Yang C, Xia Y, et al. Thrombocytopenia caused by the development of antibodies to thrombopoietin. Blood. 2001;98(12):3241-3248.

48. Cwirla SE, Balasubramanian P, Duffin DJ, et al. Peptide agonist of the thrombopoietin receptor as potent as the natural cytokine. Science. 1997;276(5319):1696-1699.

49. Broudy VC, Lin NL. AMG531 stimulates megakaryopoiesis in vitro by binding to Mpl. Cytokine. 2004;25(2):52-60.

50. Kuter DJ, Bussel JB, Lyons RM, et al. Efficacy of romiplostim in patients with chronic immune thrombocytopenic purpura: a double-blind randomised controlled trial. Lancet. 2008;371(9610): 395-403.

51. US Food and Drug Administration (FDA). FDA drug safety communication: modified risk evaluation and mitigation strategies (REMS) for Nplate (romiplostim) and Promacta (eltrombopag) [web page on the Internet]. Rockville, MD: FDA; December 6, 2011 [updated December 15, 2011]. Available from: http://www.fda.gov/drugs/ drugsafety/ucm280165/htm. Accessed August 8, 2014.

52. Bussel JB, Kuter DJ, George JN, et al. AMG 531, a thrombopoiesisstimulating protein, for chronic ITP. $N$ Engl $J$ Med. 2006;355(16): $1672-1681$.

53. Kuter DJ, Rummel M, Boccia R, et al. Romiplostim or standard of care in patients with immune thrombocytopenia. $N$ Engl J Med. 2010;363(20):1889-1899.

54. Kuter DJ, Bussel JB, Newland A, et al. Long-term treatment with romiplostim in patients with chronic immune thrombocytopenia: safety and efficacy. Br J Haematol. 2013;161(3):411-423.

55. Khellaf M, Michel M, Quittet P, et al. Romiplostim safety and efficacy for immune thrombocytopenia in clinical practice: 2-year results of 72 adults in a romiplostim compassionate-use program. Blood. 2011 118(16):4338-4345.

56. George JN, Mathias SD, Go RS, et al. Improved quality of life for romiplostim-treated patients with chronic immune thrombocytopenic purpura: results from two randomized, placebo-controlled trials. $\mathrm{Br} J$ Haematol. 2009;144(3):409-415.

57. Michel M, te Boekhorst PA, Janssens A, et al. Reduced corticosteroid use in adult patients with primary immune thrombocytopenia receiving romiplostim. Hematology. 2011;16(5):274-277.

58. Ghadaki B, Nazi I, Kelton JG, Arnold DM. Sustained remissions of immune thrombocytopenia associated with the use of thrombopoietin receptor agonists. Transfusion. 2013;53(11):2807-2812.

59. Zeng Y, Duan X, Xu J, Ni X. TPO receptor agonist for chronic idiopathic thrombocytopenic purpura. Cochrane Database Syst Rev. 2011;(7):CD008235.

60. Gernsheimer TB, George JN, Aledort LM, et al. Evaluation of bleeding and thrombotic events during long-term use of romiplostim in patients with chronic immune thrombocytopenia (ITP). J Thromb Haemost. 2010;8(6):1372-1382.

61. Saleh MN, Bussel JB, Cheng G, et al; EXTEND Study Group. Safety and efficacy of eltrombopag for treatment of chronic immune thrombocytopenia: results of the long-term, open-label EXTEND study. Blood. 2013;121(3):537-545.

62. Mahévas M, Fain O, Ebbo M, et al. The temporary use of thrombopoietin-receptor agonists may induce a prolonged remission in adult chronic immune thrombocytopenia. Results of a French observational study. Br J Haematol. 2014;165(6):865-869.

63. Leven E, Hsieh L, Ramaswamy K, McGuinn CE, Nugent D, Bussel JB. Safe and effective use of romiplostim and eltrombopag in children with ITP. ASH Annual Meeting Abstracts. 2013;311: Abstract 3541.

64. Ghanima W, Junker P, Hasselbalch HC, et al. Fibroproliferative activity in patients with immune thrombocytopenia (ITP) treated with thrombopoietic agents. Br J Haematol. 2011;155(2):248-255.

65. Boiocchi L, Orazi A, Ghanima W, Arabadjief M, Bussel JB, Geyer JT. Thrombopoietin receptor agonist therapy in primary immune thrombocytopenia is associated with bone marrow hypercellularity and mild reticulin fibrosis but not other stromal abnormalities. Mod Pathol. 2012;25(1):65-74.
66. Bussel JB, Kuter DJ, Pullarkat V, Lyons RM, Guo M, Nichol JL. Safety and efficacy of long-term treatment with romiplostim in thrombocytopenic patients with chronic ITP. Blood. 2009;113(10):2161-2171.

67. Kuter DJ, Mufti GJ, Bain BJ, Hasserjian RP, Davis W, Rutstein M. Evaluation of bone marrow reticulin formation in chronic immune thrombocytopenia patients treated with romiplostim. Blood. 2009; 114(18):3748-3756.

68. Ettrup MS, Jensen AØ, Engebjerg MC, et al. Bone marrow reticulin and collagen content in patients with adult chronic immune thrombocytopenic purpura: a Danish nationwide study. Am J Hematol. 2010;85(12):930-934.

69. Beckman EN, Brown AW Jr. Normal reticulin level in iliac bone marrow. Arch Pathol Lab Med. 1990;114(12):1241-1243.

70. Bauermeister DE. Quantitation of bone marrow reticulin-a normal range. Am J Clin Pathol. 1971;56(1):24-31.

71. Kuter DJ. The biology of thrombopoietin and thrombopoietin receptor agonists. Int J Hematol. 2013;98(1):10-23.

72. Giagounidis A, Mufti GJ, Fenaux P, et al. Results of a randomized, double-blind study of romiplostim versus placebo in patients with low/ intermediate-1-risk myelodysplastic syndrome and thrombocytopenia. Cancer. 2014;120(12):1838-1846.

73. Bussel JB, Buchanan GR, Nugent DJ, et al. A randomized, double-blind study of romiplostim to determine its safety and efficacy in children with immune thrombocytopenia. Blood. 2011;118(1):28-36.

74. Elalfy MS, Abdelmaksoud AA, Eltonbary KY. Romiplostim in children with chronic refractory ITP: randomized placebo controlled study. Ann Hematol. 2011;90(11):1341-1344.

75. Tarantino MD, Bussel JB, Geddis A, et al. Safety and efficacy of long-term open-label romiplostim dosing in thrombocytopenic pediatric patients with immune thrombocytopenia (ITP). Blood. 2013; 122(21):3530.

76. Pasquet M, Aladjidi N, Guiton C, et al; Centre de Référence National des Cytopénies Auto-immunes de l'Enfant (CEREVANCE). Romiplostim in children with chronic immune thrombocytopenia (ITP): the French experience. Br J Haematol. 2014;164(2):266-271.

77. Amgen. Safety and efficacy study of romiplostim (AMG 531) to treat ITP in pediatric subjects. In: ClinicalTrials.gov [website on the Internet] Bethesda, MD: US National Library of Medicine; 2007 [updated July 18, 2014]. Available from: http://www.clinicaltrials.gov/ct2/show/ NCT00515203. NLM identifier: NCT00515203. Accessed August 24, 2014.

78. MD Anderson Cancer Center. AMG 531 in patients with advanced malignancy receiving treatment with carboplatin. In: ClinicalTrials. gov [website on the Internet]. Bethesda, MD: US National Library of Medicine; 2005 [updated April 7, 2014]. Available from: http:// www.clinicaltrials.gov/ct2/show/NCT00147225. NLM identifier: NCT00147225. Accessed August 24, 2014.

79. MD Anderson Cancer Center. Study of AMG 531 to evaluate the safety and efficacy in patients with non-Hodgkin's lymphoma. In: ClinicalTrials.gov [website on the Internet]. Bethesda, MD: US National Library of Medicine; 2006 [updated September 4, 2014]. Available from: http://www.clinicaltrials.gov/ct2/show/study/NCT00299182. NLM identifier: NCT00299182. Accessed August 24, 2014.

80. Memorial Sloan-Kettering Cancer Center. Study of romiplostim versus observation for chemotherapy induced thrombocytopenia. In: ClinicalTrials.gov [website on the Internet]. Bethesda, MD: US National Library of Medicine; 2014 [updated August 14, 2014]. Available from: http://www.clinicaltrials.gov/ct2/show/NCT02052882?term=soff+romi plostim\&rank=1. NLM identifier: NCT02052882. Accessed October 12, 2014.

81. New York University School of Medicine. Romiplostim in increasing low platelet counts in patients with multiple myeloma receiving chemotherapy. In: ClinicalTrials.gov [website on the Internet]. Bethesda, MD: US National Library of Medicine; 2012 [updated September 12, 2014]. Available from: http://www.clinicaltrials.gov/ ct2/show/NCT01676961. NLM identifier: NCT01676961. Accessed August 24, 2014. 
82. Amgen. Dose/Schedule finding trial of romiplostim for chemotherapyinduced thrombocytopenia (CIT) in non-small cell lung cancer (NSCLC). In: ClinicalTrials.gov [website on the Internet]. Bethesda, MD: US National Library of Medicine; 2006 [updated September 18, 2013]. Available from: http://www.clinicaltrials.gov/ct2/show/ NCT00413283. NLM identifier: NCT00413283. Accessed August 24, 2014.

83. Amgen. Nplate ${ }^{\circledR}$ pregnancy exposure registry (NPER). In: ClinicalTrials. gov [website on the Internet]. Bethesda, MD: US National Library of Medicine; 2014 [updated June 24, 2014]. Available from: http:// www.clinicaltrials.gov/ct2/show/NCT02090088. NLM identifier: NCT02090088. Accessed August 24, 2014.
84. Kyowa Hakko Kirin Korea Co, Ltd. A phase 2 study to evaluate the efficacy and safety of AMG531 in aplastic anemia. In: ClinicalTrials. gov [website on the Internet]. Bethesda, MD: US National Library of Medicine; 2014 [updated March 20, 2014]. Available from: http:// www.clinicaltrials.gov/ct2/show/NCT02094417. NLM identifier: NCT02094417. Accessed August 24, 2014.

85. University of Southern California. Romiplostim in treating hepatitis c-infected patients with thrombocytopenia. In: ClinicalTrials.gov [website on the Internet]. Bethesda, MD: US National Library of Medicine; 2010 [updated July 22, 2014]. Available from: http:// www.clinicaltrials.gov/ct2/show/NCT01153919. NLM identifier: NCT01153919. Accessed August 24, 2014.

\section{Publish your work in this journal}

The Journal of Blood Medicine is an international, peer-reviewed, open access, online journal publishing laboratory, experimental and clinical aspects of all topics pertaining to blood based medicine including but not limited to: Transfusion Medicine; Blood collection, Donor issues, Transmittable diseases, and Blood banking logistics; Immunohematology; Artificial and alternative

\section{Dovepress}

blood based therapeutics; Hematology; Biotechnology/nanotechnology of blood related medicine; Legal aspects of blood medicine; Historical perspectives. The manuscript management system is completely online and includes a very quick and fair peer-review system. Visit http://www.dovepress.com/ testimonials.php to read real quotes from published authors.

Submit your manuscript here: http://www.dovepress.com/Journal-of-blood-medicine-journal 